\title{
Health Care Management Practices of Backyard Poultry Rearing in Dungarpur District of Rajasthan
}

\author{
Budharam $^{1 *}$, Lokesh Gupta ${ }^{1}$ and Lekhu Kumar ${ }^{2}$ \\ ${ }^{1}$ Department of Livestock Production Management, RCA, MPUAT, Udaipur, Rajasthan, INDIA \\ ${ }^{2}$ Department of Livestock Production Management, SKNAU, Jobner, Rajasthan, INDIA \\ *Corresponding author: Budharam; E-mail: jat.97ram@gmail.com
}

Received: 21 June, 2021

Revised: 20 July, 2021

Accepted: 23 July, 2021

\begin{abstract}
The current research deals with the Health care management practices of backyard poultry rearing in experiment area of Dungarpur district. The field of investigation of this study covered four tehsils of Dungarpur district i.e. Dungarpur, Bicchiwada, Aspur and Sagwara. The Study reveals that in health care management practices maximum respondents (85.43 per cent) had veterinary facilities, 75.00 per cent did not follow the vaccination, 87.78 per cent respondents provided vaccine to bird after hatching, 48.89 per cent respondent cleans poultry and equipment on alternate days, 48.33 per cent farmers said that veterinary person visited the respondent poultry house monthly, maximum farmers were weighing their birds weekly (64.44 per cent), all 180 respondents ( 100 per cent) used isolation distance of sick poultry birds and 49.44 per cent respondents used bamboo type poultry house in the experiment area.
\end{abstract}

\section{HIGHLIGHTS}

(0 We studied Health Care Management Practices of Backyard Poultry rearing in Dungarpur district of Rajasthan.

0 Maximum respondents provided vaccine to bird after hatching.

(0 Maximum respondents used bamboo type poultry house.

Keywords: Backyard poultry, Dungarpur, Health care, Poultry house, Vaccination

Livestock is an integral part of agriculture and plays an important role in contributing to national economy. Poultry is also a major part of livestock production in India. Poultry sector contributes about 36 per cent of total meat production in India (Department of animal husbandry, dairying and fisheries, 2018-19). Eggs contribute 3.77 per cent as value output from total livestock rearing. India shares 3.17 per cent of total poultry in the world, (Anonymous, 2018-19). The population of poultry under courtyard system is 317 million ( $20^{\text {th }}$ census). This has occurred even though the fact that rural courtyard poultry is a main part of the activity portfolio of most of the rural families. As per $20^{\text {th }}$ livestock census, there were 80.24 lacs poultry in Rajasthan, from which 30.33 lacs poultry were at backyard and remaining 49.91 lacs were at farm poultry. Dungarpur was at $\mathrm{V}^{\text {th }}$ position in the number of backyard poultry with having 1.78 lacs population after Ajmer, Udaipur, Jhunjhunu and Banswara having I $^{\text {st }}$, II $^{\text {nd }}$, $\mathrm{III}^{\mathrm{rd}}$ and $\mathrm{IV}^{\text {th }}$ rank, respectively. Backyard poultry serves as an inexpensive means for households to generate highly nutrious food commodities at minimal cost (PicaCiamarra and Otte, 2010). The paying causes for this quicker progress rate are constant increase in demand of poultry products, developed genetic potential of the birds owing to continuous and accurate selection and breeding strategies, improvement in management practices as well as health cover and availability of the quality balanced

How to cite this article: Budharam, Gupta, L. and Kumar, L. (2021). Health Care Management Practices of Backyard Poultry Rearing in Dungarpur District of Rajasthan. J. Anim. Res., 11(04): 707-710.

Source of Support: None; Conflict of Interest: None क्) 
feed. Indian poultry business is better planned and is succeeding towards renovation. Birds feed by scavenging or are provided with household scraps and crop byproducts. Backyard poultry manure can be used directly (Pal et al., 2020). cross breeding is widely used commercial production as a means of exploiting heterosis when the desired phenotype is a combination of existing breeds to impose the efficiency of the operation through the use of elit sire and dam lines. The backyard poultry are bird having desirable plumage colour with high performance compared to local indigenous bird with very small change in husbandry practice i.e. followed for the indigenous fowl, in addition to indigenous fowl crossbreed, produced using exotic breed is being used for backyard poultry farming (Das et al., 2008 and Padhi et al., 2012). The best fed and housed stock with the best genetic potential will not grow and produce efficiently if they become diseased or infested with parasites. Therefore good poultry health management is an important component of poultry production. Infectious disease causing agents will spread through a flock very quickly because of the high stocking densities of commercially housed poultry.

\section{MATERIALS AND METHODS}

The existing study was carried out in Dungarpur district of Rajasthan. Dungarpur district is situated in the south region of Rajasthan and geographically characterized by the Aravali hills. The district lies in the middle of $23.8^{\circ} \mathrm{N}$ latitude and $73.7^{\circ} \mathrm{E}$ longitude and altitude of 225 meter beyond average sea level. Dungarpur district comprises of total 8 tehsils, out of which 4 tehsils i.e. Dungarpur, Bicchiwada, Aspur and Sagwara were selected for the investigation. Three villages were selected from the each identified tehsil and total twelve villages were selected on the basis of backyard poultry birds availability in the villages. Fifteen respondents from every village were randomly selected and a total number of 180 farmers were investigated for current research. Data were collected with the help of a semi structured interview schedule and through observation. Data so collected, tabulated and analyzed as per standard statistical procedures of Snedecor and Cochran (1994).

\section{RESULTS AND DISCUSSION}

The results indicated that maximum respondents $(85.43$ per cent) had veterinary facilities and only 14.57 per cent had no facilities of veterinary (Table 1). It is clear from Table 1 that most of respondents, 75.00 per cent did not follow the vaccination and remaining 25.00 per cent treated their birds through vaccination. The results of Table 1 exhibit that 87.78 per cent respondents provided vaccine to bird after hatching and only 12.22 per cent provided it after birth. The data of Table 2 revealed that respondents of study area used 24.72 per cent kaccha, 23.60 per cent pucca, 49.44 per cent bamboo and 29.67 per cent used mixed type poultry house. It clear from Table 2 that 12.78 per cent respondents cleaned poultry and equipment daily, 48.89 per cent respondents on alternate days and 38.33 per cent respondents did this weekly. Data presented in Table 3 shows that veterinary person visited the respondent poultry house as follows 3.33 per cent weekly, 41.11 per cent fortnight, 48.33 per cent monthly and only 7.22 per cent respondents had no visit by veterinary persons. The results of data exhibited that maximum farmers were weighing their birds weekly ( 64.44 per cent), followed by $2-3$ days (46.55 per cent) and only 8.62 per cent respondent took weight of poultry birds daily (Table 3 ). It is clear from data that all 180 respondents (100 per cent) used isolation distance of sick poultry birds (Table 3 ).

It is observed that 24.72 per cent recipients used kaccha house, 23.60 per cent pucca house, 49.44 per cent used bamboo and 26.67 per cent of mixed poultry house in study area. However, Monsi and Ayodele (1989) noticed that poultry was reared in open sided house with a concrete floor covered with wood shadings. The maximum recipients $(85.43 \%)$ have veterinary facilities and only 14.57 percent have not any facilities of veterinary. The most of recipients, 75.00 percent not follow vaccination for poultry. The $87.78 \%$ recipients provide vaccine to bird after hatching and only $12.22 \%$ provide it after bird.

The mean number of eggs consumed and sold per year were 110 and 570, respectively. However, Singh et al. (2003) reported higher number of eggs consumed per week (9.45) as compared to the present study. The mean number of fowls disbursed and sold per year was 10.11 and 28.21, respectively. Bendfeldt et al. (2006) described that consuming or selling the fowls were 0-20 birds.

It was discovered that market for trade of poultry product was main problems in the study areas, as there is no trade facility in selected areas under investigation. These results are in agreement with the results of Bhattu et al. (1999) 
and Bendfeldt et al. (2006). Instead of most (46.25\%) of recipients showed availability of developed strain of bird as a main constraints in study area. The consequences of current research are in agreement with the reports of Sing and Jilani (2005) and Mandal et al. (2006). Maximum recipients of research area placed problems as infection occurrence, predators, fitness service and feed accessibility on rank II, III, IV and V. Similarly Mandal et al. (2006) reported high occurrence of disease and predators as key constraints. Though Conroy et al. (2005) reported the predation as main as, or more important than infection. Thakre and Sarkar (2004) perceived that lake of health care facility as one of the main constraints. Further, Barua and Yoshimura (1997) discovered that scarcity of feed and high occurrence of disease as key problems.

Table 1: Distribution of respondents on the basis of availability of veterinary facilities, vaccination followed and days of vaccination

\begin{tabular}{lll}
\hline Item & Number of respondents & Percent \\
\hline Availability Veterinary Facility & \\
\hline Yes & 129 & 85.43 \\
No & 22 & 14.57 \\
Total & 151 & 100.00 \\
\hline Vaccination & \\
\hline Yes & 45 & 25.00 \\
No & 135 & 75.00 \\
Total & 180 & 100.00 \\
\hline Days of Vaccination & & \\
\hline After birth & 22 & 12.22 \\
Hatching & 158 & 87.78 \\
Total & 180 & 100.00 \\
\hline
\end{tabular}

Table 2: Distribution of respondents on the basis of type of backyard poultry houses used and cleaning of poultry house and equipment's

\begin{tabular}{lll}
\hline Item & Number of respondents & Percent \\
\hline Poultry house & & \\
\hline Kachha & 22 & 24.72 \\
Pucca & 21 & 23.60 \\
Bamboo & 89 & 49.44 \\
Mix type & 48 & 26.67 \\
Total & 180 & 100.00 \\
\hline
\end{tabular}

\begin{tabular}{lll}
\hline \multicolumn{3}{l}{ Cleaning of poultry house and equipment's } \\
\hline Daily & 23 & 12.78 \\
Alternate days & 88 & 48.89 \\
Weekly & 69 & 38.33 \\
Total & 180 & 100.00 \\
\hline
\end{tabular}

Table 3: Distribution of respondents on the basis of monitoring by veterinary persons, weighing of chicks and Segregation of sick birds

\begin{tabular}{lll}
\hline Item & \multicolumn{1}{l}{ Number of respondents } & Percent \\
\hline Monitoring by Veterinary Persons & \\
\hline Weekly & 6 & 3.33 \\
Fortnightly & 74 & 41.11 \\
Monthly & 87 & 48.33 \\
No & 13 & 7.22 \\
Total & 180 & 100.00 \\
\hline Weighing of Chicks & \\
\hline Daily & 10 & 8.62 \\
$2-3$ days & 54 & 46.55 \\
Weekly & 116 & 64.44 \\
2 weeks & 0 & 0.00 \\
Total & 180 & 100.00 \\
\hline Segregation of Sick Birds & \\
\hline Yes & 180 & 100.00 \\
No & 0 & 0.00 \\
Total & 180 & 100.00 \\
\hline
\end{tabular}

\section{CONCLUSION}

The study concluded that, in health care management practices maximum respondents had veterinary facilities, most of the respondents did not follow the vaccination and respondents provide vaccine to bird after hatching. Maximum respondent cleans poultry and equipment on alternate days not regular, most of farmers said that veterinary person visited the respondent poultry house monthly, maximum farmers were weighing their birds weekly, all respondents used isolation distance of sick poultry birds and maximum respondents used bamboo type poultry house in the investigation area.

\section{ACKNOWLEDGEMENTS}

It is a great pleasure for me to express sincere and deepest sense of gratitude and indebtedness to Department of 
Livestock Production Management, Rajasthan College of Agriculture, MPUAT, Udaipur for providing all the necessary facilities for conducting this experiment.

\section{REFERENCES}

Anonymous, 2018-19. Department of animal husbandry, dairying and fisheries, Ministry of agriculture and farmers welfare, Govt. of India.

Barua, A. and Yoshimura, Y. 1997. Rural poultry keeping in Bangladesh. Wor. Poult. Sci. J., 53: 387-394.

Bendfeldt, E.S., Peer, R.W. and Flory, G.A. 2006. In house compositing as a rapid response to avaian influenza. Biology, 47: $38-42$

Bhattu, B.S., Gupta, S.C. and Sharma, R.K. 1999. A study on region wise constraints encountered by broiler farmers in Haryana. Ind. J. Anim. Res., 33: 131-133.

Conroy, C., Sparks, N., Chandrasekarn, D., Sharma, A., Shindey, D., Singh, L.R., Natarajan, A. and Anitha, K. 2005. The significance of production as a constraint in scavenging poultry systems: some finding from India. Lives. Res. Rur. Devel., 17(6): 70 .

Das, S.C., Chowdhury, S.D., Khatum, M.A.,Nishibori, M., Isobe, N. and Yoshimura, Y. 2008. Poultry production profile and expected future projection in Bangladesh. Wor. Poult. Sci. J., 64: 99-118.
Mandal, M.K., Khandekar, N. and Khandekar, P. 2006. Backyard poultry farming in Bareily district of Uttar Pradesh, India: an analys's. Lives. Res. Rur. Dev., 18: 101.

Monsi, A. and Ayodele, A.O. 1989. Water intake of broilers raised during the rainy season in Rivers State of Nigeria. $J$. Anim. Prod. Res., 9: 25-41.

Pal, S., Prakash, B., Kumar, A. and Singh, Y. 2020. Resource Utilization for Better Livelihood of the Rural Population. Inter. J. Curren. Microbio. Appl. Sci., 9(5): 2361-2371.

Padhi, M.K., Rajkumar, U., Haunshi, S., Niranjan, M., Panda, A.K., Bhattacharya, T.K. Reddy, M.R., Bhanja, S.K. and Reddy, B.L.N. 2012. Comparative evaluation of male line of Vanaraja, control broiler, Vanaraja commercial in respect to juvenile and carcass quality traits. Ind. J. Poult. Sci., 47: 136-139.

Singh, D.P., Johri, T.S. Singh, U.B., Narayan, R., Singh, D. and Saran, S. 2003. Implemented integrated approach for traditional village poultry production. Bhartiya Krishi Anusandhan Patrika, 18: 93-101.

Singh, C.B. and Jilani, M.H. 2005. Backyard poultry farming in garhwal Himalayas. Ind. J. Poult. Sci., 40: 195-198.

Thakre, H.S. and Sarkar, J.D. 2004. Constraints in adoption of poultry production technology for poultry farming in Raipur. J. Sait. Crop., 14: 358-361. 